\title{
Balkanologie
}

Balkanologie Revue d'études pluridisciplinaires

Vol. $16 n^{\circ} 1 \mid 2021$

Au-delà de la "route des Balkans ": mondes sociaux des circulations

\section{Radina Vučetić, Coca-Cola Socialism: Americanization of Yugoslav Culture in the Sixties}

Budapest, Central European University Press, 2018

\section{Brendan Hebert}

\section{OpenEdition}

Journals

Édition électronique

URL : https://journals.openedition.org/balkanologie/3168

DOI : 10.4000/balkanologie.3168

ISSN : 1965-0582

Éditeur

Association française d'études sur les Balkans (Afebalk)

Référence électronique

Brendan Hebert, "Radina Vučetić, Coca-Cola Socialism: Americanization of Yugoslav Culture in the Sixties », Balkanologie [En ligne], Vol. 16 n 1 | 2021, mis en ligne le 01 juin 2021, consulté le 03 octobre 2021. URL : http://journals.openedition.org/balkanologie/3168 ; DOI : https://doi.org/10.4000/

balkanologie.3168

Ce document a été généré automatiquement le 3 octobre 2021.

(c) Tous droits réservés 


\title{
Radina Vučetić, Coca-Cola Socialism: Americanization of Yugoslav Culture in the Sixties
}

\author{
Budapest, Central European University Press, 2018
}

\section{Brendan Hebert}

\section{RÉFÉRENCE}

Vučetić, Radina, 2018, Coca-Cola Socialism: Americanization of Yugoslav Culture in the Sixties, Budapest, Central European University Press, 334 pages, ISBN : 978-963-386-200-1

1 Six ans après sa publication initiale sous le titre de "Koka-kola socijalizam ", la monographie révisée de Radina Vučetić, spécialiste d'histoire culturelle et professeure à l'Université de Belgrade, est désormais accessible à un public non serbophone grâce à sa traduction anglaise par John K. Cox. La monographie historique de Vučetić s'inscrit dans le champ d'études des échanges culturels entre les blocs capitaliste et communiste pendant la guerre froide. Elle va à l'encontre de l'idée unidimensionnelle selon laquelle l'histoire de ce conflit représenterait un choc entre deux blocs étanches ayant chacun son interprétation du monde, une conception qui néglige entre autres l'expérience des pays non alignés et des États, tels la Yougoslavie, qui se livraient à un délicat exercice d'équilibriste entre les deux blocs.

2 La spécificité de cette étude est de centrer l'analyse sur les transferts culturels entre la République fédérative socialiste de Yougoslavie (RFSY) et le bloc occidental, en particulier les États-Unis, mais aussi de s'intéresser à la place de ces transferts dans les relations extérieures de l'État yougoslave et dans les rapports que cet État entretient avec ses propres citoyen.ne.s. La monographie utilise comme cadre de référence conceptuel l'américanisation, un phénomène d'imposition culturelle des coutumes, habitudes, idées, valeurs et produits américains, activement encouragée par le gouvernement américain pour servir ses intérêts géopolitiques. Prenant ce cadre 
comme grille de lecture, Vučetić s'intéresse aux modalités, causes et conséquences de l'appropriation des cultures occidentale et américaine par et pour les Yougoslaves ordinaires. L'autrice se focalise uniquement sur la décennie des années 1960, une période d'entente politique entre la RFSY et les pays européens, et de libéralisme politique relatif avant le revirement autoritaire de la décennie suivante. Vučetić évite l'écueil qui consisterait à considérer le pays d'accueil du transfert comme un simple réceptacle et met l'accent sur le fait que cette importation culturelle était un phénomène souhaité à la fois par le gouvernement et par les citoyens yougoslaves ordinaires, qui ont adapté et remodelé les importations culturelles pour servir leurs intérêts propres.

3 En effet, la thèse principale de l'autrice est la suivante : l'importation relativement sans restriction de produits culturels américains en RFSY était tout aussi utile au gouvernement américain que yougoslave. Du côté américain, l'exportation planifiée de biens culturels et de consommation ne servait pas tant à faire chuter le socialisme d'État en Yougoslavie, ce qui n'était pas le but de la stratégie américaine. Il s'agissait plutôt de creuser le fossé entre Moscou et Belgrade et de saper l'homogénéité du bloc communiste, en faisant miroiter aux États satellites de l'URSS l'existence de chemins multiples vers le communisme. En face, le régime titiste se servait de l'accès relativement facile aux produits occidentaux pour promouvoir une image libérale du pays à l'étranger capitaliste et communiste, malgré des formes de censure dans le domaine artistique et un système politique autoritaire. Plus important encore, l'américanisation de la vie yougoslave servait de tampon au mécontentement intérieur en alimentant un sentiment de liberté et de bien-être matériel, par opposition aux sociétés socialistes moins « développées ».

4 Il faut cependant noter, comme le fait Vučetić, que malgré la tolérance vis-à-vis de formes culturelles et de consommation venant des États-Unis, qui était parfois même encouragées, les autorités yougoslaves étaient beaucoup moins favorables à maintenir un visage libéral quand le contenu critiquait l'État yougoslave ou le système socialiste, recourant alors à la censure voire la répression. L'autrice utilise donc comme fil conducteur tout au long de l'ouvrage la métaphore du dieu romain à double visage Janus pour décrire le positionnement de la Yougoslavie entre les blocs : le pays montre une facette de sa réalité au bloc occidental, une autre au bloc soviétique, interagissant avec les deux sans jamais se tourner pleinement vers un camp ni vers l'autre.

5 L'ouvrage se divise en quatre chapitres de structure similaire, dans lesquels l'autrice présente de multiples exemples de formes de culture savante, de culture de masse ou culture pop dans lesquelles on observe l'articulation d'éléments importés des ÉtatsUnis ou influencés par la culture américaine. Dans chaque chapitre, sont présentés en contrepoint des cas d'adoption d'éléments américains dans le Royaume yougoslave des années 1920 et 1930, dans l'Union soviétique, ou encore dans d'autres pays socialistes (Pologne, Tchécoslovaquie, RDA), ce qui permet d'historiciser l'introduction de ces phénomènes en Yougoslavie socialiste et d'offrir les bases d'une dimension comparative à l'ouvrage. Ce faisant, Vučetić évite de souscrire au mythe de l'exceptionnalisme yougoslave en soulignant les occasions où d'autres États socialistes ont adopté des dimensions ou des produits de la culture américaine bien avant la RFSY, parfois à la surprise des habitants de ce pays.

6 Le premier chapitre traite du cinéma américain, fortement importé du fait de son succès commercial, aidé en cela par le prix artificiellement bas fixé par le 
gouvernement américain, et très apprécié du public yougoslave. Le gouvernement de la RFSY se saisit de cet engouement populaire pour appuyer sa légitimité, s'appropriant le genre du western pour le reformuler dans les épopées de partisans combattant les nazis ou les nationalistes albanais et attirant des stars d'Hollywood très populaires parmi le grand public pour jouer dans des coproductions. Ce chapitre souligne aussi le double jeu des autorités yougoslaves : tout en censurant sur le territoire national les cinéastes dits de la "Vague noire », très critiques de la vie quotidienne yougoslave, le pouvoir favorisait l'exportation de ces films vers l'Occident, où ils servaient à montrer le caractère libéral du régime.

7 Le second chapitre se focalise sur la musique : les États-Unis, ne pouvant pas faire concurrence aux Soviétiques dans le domaine de la « haute culture » comme le ballet ou la musique classique, cherchaient plutôt à promouvoir l'idée de liberté par l'intermédiaire du jazz et du rock, en particulier en finançant la station de radio Voice of America. La reconnaissance institutionnelle du jazz, notamment, servait à découpler la Yougoslavie et l'URSS, un fait qui n'a échappé ni aux autorités américaines ni aux autorités yougoslaves: alors que Khrouchtchev raillait cette forme artistique, Tito célébrait son anniversaire avec un ensemble de jazz, envoyant ainsi le double message de sa libéralité à l'Occident et des avantages matériels, y compris en termes de culture, d'une "voie séparée » au socialisme. Le rock, une forme de musique beaucoup plus révoltée dans certains pays socialistes, a été similairement approprié par le gouvernement pour neutraliser son potentiel contestataire. Dans les années 1960, en échange de soutien matériel (organisation de festivals, droit de répéter dans des maisons de culture ou bâtiments municipaux), les rockers yougoslaves acceptaient souvent de s'autocensurer et de limiter leurs chansons à des sujets apolitiques. De cette manière, le pouvoir a pu canaliser la jeunesse du pays vers des intérêts qu'il jugeait non menaçants.

Bien que la majorité des efforts d'américanisation aient porté sur la culture populaire, qui touchait un nombre plus important à la fois de personnes et de couches sociales politiquement influentes, ils ont aussi touché la «haute culture " et les milieux intellectuels. Le troisième chapitre montre l'insertion de courants artistiques américains avant-gardistes en Yougoslavie, tout en utilisant cette insertion pour souligner le caractère janusien du régime. En termes de forme, le régime montra une grande ouverture aux tendances avant-gardistes occidentales, autorisant non seulement l'expressionnisme abstrait et le pop art, mais aussi des productions théâtrales qui incluaient des manifestations provocatrices telles que le crachat sur le public ou la nudité sur scène. Ce faisant, il espérait prévenir le mécontentement parmi l'élite intellectuelle en faisant miroiter une forme d'expression libre. Cependant, si la forme était permissive, tout contenu critiquant l'idéologie de «la fraternité et [de] l'unité des peuples ", ainsi que le dogme communiste, était proscrit, conduisant à une censure artistique qui s'amplifia alors que la décennie se clôturait, préfigurant le raffermissement politique des années 1970. Cela dit, il faut éviter, comme le fait habilement Vučetić, une opposition entre liberté américaine et répression socialiste: les États-Unis censuraient l'image du pays présentée aux consommateurs yougoslaves en limitant leurs exportations d'œuvres artistiques à celles qui donnaient une image positive du pays. Cependant, les citoyens yougoslaves pouvaient lire les œuvres de Henry Miller sans censure, chose impossible aux États-Unis où ces livres furent expurgés de leur contenu sexuellement explicite. 
9 Centré sur l'américanisation de la vie quotidienne, le quatrième et dernier chapitre se focalise sur une large panoplie de phénomènes importés de la culture américaine ou influencés par elle : les dessins animés et les bandes dessinées, les séries télévisées, la mode, la sous-culture hippie, le Coca-Cola et d'autres éléments de la culture de consommation, tels les supermarchés. Cette "Coca-Colonisation» permit à la population yougoslave d'accéder à des biens de consommation difficiles d'accès dans les autres pays socialistes et de réorienter leur cartographie culturelle vers l'Occident, tout en permettant au régime de maintenir la façade d'un socialisme à visage humain offrant un meilleur bien-être économique, malgré la répression politique.

On pourrait cependant reprocher à cette monographie de souscrire sans grande critique à l'opposition entre l'image d'un Occident attractif et un socialisme d'État gris et répressif - hors RSFY bien sûr, où la vie a été suffisamment américanisée. Dans sa conception de l'américanisation, l'autrice néglige peut-être également la contribution des pays européens au transfert culturel: un Yougoslave achetait beaucoup plus facilement des jeans à Trieste que des jeans américains et la politique d'émigration ouvrit la porte, pour des centaines de milliers de travailleurs yougoslaves, à la vie en République fédérale d'Allemagne, en Autriche ou en Italie. Cependant, ce livre reste un apport essentiel à l'analyse des relations et échanges culturels entre la RSFY et les États-Unis au cours de cette période.

\section{AUTEURS}

\section{BRENDAN HEBERT}

Université Paris-Nanterre

brendanl.hebert[at]gmail.com 